\title{
INVESTIGATING THE RELATIVE IMPORTANCE OF THE CEAB GRADUATE ATTRIbUTES: STUdy DESIGN AND INITIAL Findings
}

\author{
Jillian Seniuk Cicek ${ }^{a *}$, Sandra Ingram ${ }^{a}$, Danny Mann ${ }^{b}$, and Robert Renaud ${ }^{d}$, \\ ${ }^{\mathrm{a}}$ Centre for Engineering Professional Practice and Engineering Education; ${ }^{\mathrm{b}}$ Biosystems Engineering; \\ ${ }^{c}$ Educational Administration, Foundations \& Psychology, Faculty of Education; \\ University of Manitoba, MB, Canada \\ umseniuk@myumanitoba.ca*
}

\begin{abstract}
This study represents the PhD thesis research of the lead author. The greater study is designed as a mixed-methods explanatory case study. The overarching objective is to explore whether the CEAB graduate attributes are emphasized in the engineering programs in the Faculty of Engineering at the University of Manitoba in the most optimal way. The first phase of the study is designed to determine the relative importance and the levels of dependencies of the graduate attributes across three engineering stakeholder groups: faculty, students, and industry members. In this paper, the design and methodology of the first phase of this mixed methods research study are explained, and the preliminary findings from the participation rates and participants' familiarity with the graduate attributes on the survey data are presented. Results show that a sizable percentage of students, faculty and industry members are not highly familiar with the CEAB graduate attributes. Therefore, work to develop a common knowledge about the CEAB graduate attributes needs to continue.
\end{abstract}

Keywords: CEAB graduate attributes; engineering stakeholder perceptions; relative importance; attribute dependencies; mixed methods explanatory case study; survey

\section{INTRODUCTION \& MOTIVATION}

Engineering accreditation boards have moved away from a quality assurance model focused on documenting inputs, to an outcomes-based model focused on assessing and improving students' learning [1][2]. Accredited engineering programs are now required to demonstrate that their students are competent in a number of areas [3][4]. For Canadian accredited programs, the Canadian Engineering Accreditation Board (CEAB) has identified 12 graduate attributes that comprise a variety of skills, knowledge, attitudes, values, and behaviours [2] that students must show competence in by graduation. Canadian institutions seeking CEAB accreditation are responsible for developing learning outcomes and using outcomes-based pedagogical practices to afford students the opportunity to demonstrate these attributes
$[5][6][7][8]$. This requires that accredited programs develop curricula that are constructively aligned with their educational objectives, teaching methodologies, and assessment tools in order to facilitate students' competencies in these areas [9][10].

Today, engineering educators are already contemplating how to design pedagogies for the Engineer of 2050. Terms, such as the 'T-shaped professional,' are emphasizing the development of both the professional and technical skillsets [11]. In engineering, these comprise of the technical skills unique to the engineering profession, such as engineering knowledge and use of engineering tools, problem analysis, investigation, and design, coupled with the intrapersonal skills required of graduates to work successfully, ethically and professionally, and communicate effectively in multidisciplinary teams while negotiating an environmentally and socially challenging, culturally complex, diverse world. As stated, engineering educators have already identified the attributes inherent to developing the Tshaped engineering professional; however, the relative importance of these attributes and their interconnectivity has yet to be explored.

In order to design engineering programs to support the consistent and effective development of T-shaped graduates, engineering educators need to have a clear understanding of the relative importance of each of the $12 \mathrm{CEAB}$ graduate attributes, and if and how each attribute is dependent on another attribute. As engineering educators are preparing their students to enter the professional world, knowing how the graduate attributes manifest in stakeholders' respective engineering domains is vital to developing a common understanding of the skills, knowledge, behaviours, values and attitudes that are essential for our future engineers. Once the relative importance and dependencies of the graduate attributes are established, findings can be used to determine the content validity of engineering programs, and to inform the improvement and design of authentic, outcomes-based engineering curricula in order to graduate engineers who are optimally prepared for the demands of industry.

This research represents the $\mathrm{PhD}$ thesis of the lead author. The greater study is designed as a mixed-methods 
explanatory case study [12][13][14]. The overarching objective is to explore whether the CEAB graduate attributes are emphasized in the engineering programs in the Faculty of Engineering at the University of Manitoba in the most optimal way. The study will be executed in three phases. The first phase is designed to determine the relative importance and the levels of dependencies of the graduate attributes across three engineering stakeholder groups comprised of faculty, students, and industry members in all engineering areas. In this paper, the design and methodology of the first phase of this mixed methods research study are explained, and some preliminary findings from the participation and demographic questions on the survey data are presented.

\section{THEORETICAL AND EPISTEMOLOGICAL PERSPECTIVES}

The theoretical position underlying this research study is interpretivism, as the meanings of individuals' understandings of the graduate attributes are investigated. The underlying epistemological perspective is that truth is constructed, contextualized, and dependent on the individual and the researcher [15]. This research study design facilitates stakeholders' interacting with the graduate attributes through the intersection of the CEAB definitions and their own understandings of, and experiences with the knowledge, skills and behaviours of which the attributes are comprised. These understandings are based on the engineering role that stakeholders inhabit, i.e., engineering student, engineering faculty, engineering industry member, and the engineering areas that they identify with within their bounded world. Determining the relative importance and dependencies of the graduate attributes and then exploring stakeholders' understandings of the findings will facilitate participants' meaning-making, which further underscores the epistemology of constructivism [16]. This part of the study is interpretive in scope, with the objective to understand how stakeholders perceive how the graduate attributes, and how the graduate attributes are manifest in industry for a new engineering graduate in order to effect valuable changes within the design of engineering curricula [17].

\section{METHODS}

\subsection{Survey Development}

One close-ended rating survey was designed for Phase 1 of the research. The survey was developed to address three areas: demographic information; relative importance of the graduate attributes; and attribute dependencies. The demographic information was purposed to delineate the stakeholder group (i.e., student, faculty or industry); the engineering area (i.e., Biosystems, Civil, Computer, Electrical, Mechanical or Other); the number of years as a student, faculty, EIT or P.Eng., and participants' familiarity with the CEAB graduate attributes. The latter category was designed with a four-item forced choice confidence scale [18], giving participants the following classifications to choose from when asked: Are you familiar with the CEAB graduate attributes?

\section{No-I haven't heard of them/I've heard of them but can't recall them \\ Somewhat - I know a few of them \\ Yes - I know them, I can list them \\ Yes, very familiar -I know them, I can list them and \\ define them}

The second part of the survey was comprised of a 2part rating questionnaire, where participants were asked to rate the frequency and criticality of each of the graduate attributes based on two questions:

How often do you think an Engineer-in-Training (EIT) at the beginning of his/her career will perform a task that clearly requires this graduate attribute?

What do you think will be the potential effect on workplace performance for an Engineer-in-Training (EIT) at the beginning of his/her career if he/she does not have a sufficient level of competency for this graduate attribute?

Participants were given a list of the 12 graduate attributes and the $\mathrm{CEAB}$ definition for each attribute, along with a 5-point Likert scale for frequency, shown in Table 1, and a 5-point Likert scale for criticality, shown in Table 2.

Table 1: Frequency scale.

\begin{tabular}{|c|c|c|c|c|}
\hline 1 & 2 & 3 & 4 & 5 \\
\hline $\begin{array}{c}\text { Rarely } \\
1-2\end{array}$ & $\begin{array}{c}\text { Sometimes } \\
\text { times/year }\end{array}$ & $\begin{array}{c}\text { Regularly } \\
\text { times/month }\end{array}$ & $\begin{array}{c}\text { Quite } \\
\text { often } \\
\text { times/week } \\
\text { once per } \\
\text { day }\end{array}$ & $\begin{array}{c}\text { All the } \\
\text { time } \\
\text { several } \\
\text { times/day }\end{array}$ \\
\hline
\end{tabular}

Table 2: Criticality scale.

\begin{tabular}{|c|c|c|c|c|}
\hline 1 & 2 & 3 & 4 & 5 \\
\hline $\begin{array}{c}\text { No } \\
\text { consequence } \\
\text { (nothing to } \\
\text { either correct } \\
\text { or repeat) }\end{array}$ & $\begin{array}{c}\text { Minor } \\
\text { consequence } \\
\text { (little or no } \\
\text { harm, damage } \\
\text { or } \\
\text { inconvenience, } \\
\text { can correct } \\
\text { without help) }\end{array}$ & $\begin{array}{c}\text { Moderate } \\
\text { consequence } \\
\text { (Notable harm, } \\
\text { damage or } \\
\text { inconvenience, } \\
\text { may need help } \\
\text { to correct) }\end{array}$ & $\begin{array}{c}\text { Major } \\
\text { consequence } \\
\text { (Serious harm, } \\
\text { damage or } \\
\text { disruption, } \\
\text { likely need } \\
\text { help to correct) }\end{array}$ & $\begin{array}{c}\text { Extreme } \\
\text { consequence } \\
\text { (Irreversible or } \\
\text { irreparable } \\
\text { harm or } \\
\text { damage, } \\
\text { resulting in } \\
\text { injuries, death } \\
\text { or destruction } \\
\text { of } \\
\text { material/natural } \\
\text { world, and/or } \\
\text { reputation) }\end{array}$ \\
\hline
\end{tabular}

Participants were asked to record the frequency and criticality for each of the 12 graduate attributes. The 
frequency and criticality scales were developed under the guidance of, and informed by the work of Dr. Robert Renaud [19].

In the third part of the survey, participants were asked to score the dependency of each attribute on every other attribute based on a 5-point percentage scale of 100, 75, 50, 25, and $0 \%$. Participants were asked:

Based on your experience, please indicate on a percentage scale that ranges from $100 \%=$ total dependency to $0 \%=$ no dependency (see [scale] below), the degree to which you feel that the attribute listed on the left is dependent on, or requires, the attribute listed on the right for an Engineer-in-Training (EIT) at the beginning of his/her career.

3.1.1 Piloting Survey. Five Engineers-in-Residence and three senior year engineering students from the Faculty of Engineering at the University of Manitoba piloted the survey before data collection commenced. Several changes were made as a result.

Modification to the phrasing of the demographic question regarding number of years as an Engineer was made to reflect pilot participants' feedback (i.e., participants questioned what specifically was being asked: Number of years as an Engineer since graduation? As a P.Eng.? Since birth?, etc.). Adjustments to the phrasing of the survey questions were also made. The survey originally asked: How often would a professional engineer perform a task that clearly requires this graduate attribute? This was changed to read: How often do you think an Engineer-in-Training (EIT) at the beginning of his/her career will perform a task that clearly requires this graduate attribute? (Changes underlined.) This question was rephrased to ask participants what they think the criticality and frequency of each graduate attribute would be, allowing for participants to answer the questions even if they had no experience in the field (i.e., a student). Secondly, changing professional engineer to Engineer-in-Training (EIT) at the beginning of his/her career increased the content-related validity of the survey [20]. The purpose of this study is to determine the relative importance of the graduate attributes for the purpose of engineering program validation and improvement. This will ultimately enhance these targeted competencies in the engineers who graduate from our programs, better preparing them for their transition into industry. Therefore, we are interested in the relative importance of the graduate attributes at the point of transition from student to graduate engineer in order to optimally prepare students for their work in industry. Demarcating the engineering profile as an EIT at the onset of an engineering career more clearly met the objectives of the study. The final change, based on pilot feedback, was to add an example to the instructions of the Dependency
Scoring form to demonstrate for participants how we intended them to think about the question. The example read as follows:

For example, in the first pair, you should think about the degree to which an Engineer-in-Training (EIT) at the beginning of his/her career who is doing something that involves A Knowledge Base for Engineering depends on, or requires, Problem Analysis.

\begin{tabular}{|c|c|c|c|c|c|c|}
\hline & $100 \%$ & $75 \%$ & $50 \%$ & $25 \%$ & $0 \%$ & \\
\hline A & & & & & & $\begin{array}{c}\text { Problem } \\
\text { Analysis }\end{array}$ \\
$\begin{array}{c}\text { Knowledge } \\
\text { Base for } \\
\text { Engineering }\end{array}$ & & & & & & \\
\hline
\end{tabular}

You are being asked to consider all 12 graduate attributes individually in relation to every other graduate attribute using the following scale:

100\% - Whenever an Engineer-in-Training (EIT) at the beginning of his/her career does something that involves using his/her Knowledge Base it will always depend on/require Problem Analysis.

75\% - Whenever an Engineer-in-Training (EIT) at the beginning of his/her career does something that involves using his/her Knowledge Base it will often depend on/require Problem Analysis.

50\% - Whenever an Engineer-in-Training (EIT) at the beginning of his/her career does something that involves using his/her Knowledge Base it will sometimes depend on/require Problem Analysis.

25\% - Whenever an Engineer-in-Training (EIT) at the beginning of his/her career does something that involves using his/her Knowledge Base it will seldom depend on/require Problem Analysis.

0\% - Whenever an Engineer-in-Training (EIT) at the beginning of his/her career does something that involves using his/her Knowledge Base it will never depend on/require Problem Analysis.

The percentage symbol was also added to each column of the survey where the numeric scale was delineated for increased clarity.

\subsection{Ethics and University Approval}

Ethics approval for the study has been granted through the Education and Nursing Research Ethics Board (ENREB) at the University of Manitoba. Additionally, permission to survey University of Manitoba faculty and 
student was sought from and approved by the Office of Institutional Analysis at the University of Manitoba, and by the Dean of Engineering.

\subsection{Target Population \& Proposed Dissemination}

Participants for Phase 1 of the study comprised of three University of Manitoba engineering stakeholder groups: senior year undergraduate engineering students enrolled in Capstone, engineering faculty, and Manitoba industry members associated with the Faculty of Engineering through Friends of Engineering at the University of Manitoba or through our provincial professional engineer licensure body (formerly known as APEGM, now called Engineers Geoscientists Manitoba). Friends of Engineering was established in May 2008 and is comprised of a group of Manitoba industry members who are committed to a partnership with the $U$ of $M$ Faculty of Engineering to support excellence in engineering education [21].

At the time of data capture (mid December 2015 end of January 2016), there were approximately 91 faculty in Engineering, as well as several hundred senior year undergraduate students from the Departments of Biosystems, Civil, Electrical and Computer, and Mechanical Engineering collectively, and 70 engineering industry Friends of Engineering members. Based on these numbers, the target sample size required for a reliable, valid, and relevant analysis for each stakeholder group was calculated on a standard deviation of .2, a $95 \%$ confidence level, and a confidence interval of $+/-5 \%$ to $+/-10 \%$ as follows [22]:

$$
\mathrm{ss}=2^{2} *(\mathrm{p}) *(1-\mathrm{p})
$$

As a result, although requests for participation were sent to every member of all three of the stakeholder groups, the goal for survey participation was between 49-121 students, 37-67 faculty, and 33-55 industry member participants (see Table 3).

\subsection{Data Capture}

Data were gathered via the close-ended rating/scoring survey that was made available either electronically on SurveyMonkey or via email, or in paper form. Emails requesting participation were sent to all engineering faculty and all senior students taking Capstone through the four engineering departments (Biosystems, Civil, Electrical and Computer (ECE), and Mechanical). Additionally, the $\mathrm{PhD}$ researcher visited one Biosystems, Civil and ECE Capstone class each to request student participation (the Civil Capstone could not accommodate at the time that data were being collected). Industry members were sent email participation requests through
Engineers Geoscientists Manitoba's weekly ENews, and through Friends of Engineering's mailing list.

Participation for all stakeholders was optional and confidential. Data from the surveys are anonymous, as participants were asked to refrain from identifying themselves on the documents, and SurveyMonkey was adjusted so that the IP addresses of electronic survey participants were not captured.

\subsection{Proposed Analysis \& Research Phases}

The first phase of the study will be a quantitative determination of the relative importance and dependency ratings of the graduate attributes, analyzed using descriptive statistics and inferential statistics, such as one-way ANOVA [23][24], adaptive conjoint analysis (ACA) [25] and/or cluster analysis [26]. Data will be analyzed to determine the largest relative importance of the graduate attributes; the comparative importance of the graduate attributes; and the percentage of the engineering program that each attribute should occupy based on stakeholders' perceptions of the graduate attributes. Relative importance will be calculated as:

$$
\mathrm{I}_{\mathrm{i}}=\mathrm{F}_{\mathrm{i}} \mathrm{C}_{\mathrm{i}}[19][24]
$$

The data will be analyzed by stakeholder group (faculty, students, and industry) and engineering area (within case), as well as holistically, as one group (engineering stakeholders of the University of Manitoba) (across case).

\section{FINDINGS}

At this time, the data have just been entered and cleaned, and extensive analyses have yet to be conducted. For the purposes of this paper, participation data and familiarity with the graduate attributes will be reported on.

\subsection{Participation}

The total number of participants, once data were cleaned, was 220. One of these participants did not identify his/her stakeholder group. Therefore 219 participants' data will be analyzed. Seven participants identified with more than one stakeholder group, with one participant identifying as student/faculty; one identifying as student/faculty/industry; and five identifying as faculty/industry. For these labels, faculty trumped both student and industry identities (i.e., all seven participants were labeled faculty). This decision was based on the data collected from pilot participants. Five of the pilot participants were Engineers-inResidence in the faculty. Engineers-in-Residence (EIR) 
are industry members who, in partnership with industry and the Faculty of Engineering, are hired to teach courses in the faculty designed to meet specific industry needs. Four of the EIRs who completed the pilot forms, despite having a number of years of industry experience, all identified themselves as faculty. Survey participants who labeled themselves as faculty/industry or student/faculty/industry were assumed by the researcher to be Engineers-in-Residence. Therefore, they were ultimately placed into the Faculty stakeholder group, consistent with how the EIRs who piloted the survey identified themselves.

Overall, percentage of participation was approximately $53 \%$ students; $51 \%$ faculty; and $69 \%$ industry (see Table 3).

Table 3: Survey participation per stakeholder groups.

\begin{tabular}{|l|c|c|c|c|}
\hline & Population & $\begin{array}{c}\text { Targeted } \\
\text { Range }\end{array}$ & $\begin{array}{c}\text { \# of } \\
\text { participants }\end{array}$ & $\%$ \\
\hline Students & 235 & $49-121$ & 125 & 53.19 \\
\hline Faculty & 91 & $37-67$ & 46 & 50.55 \\
\hline Industry & 70 & $33-55$ & 48 & 68.57 \\
\hline
\end{tabular}

Participation rates for all stakeholder groups fell within the survey sample size range, with the student stakeholder participation rate meeting the $+/-5 \%$ confidence interval, and industry and faculty stakeholder rates falling within the $+/-5 \%$ and $+/-10 \%$ confidence interval range.

\subsection{Participants' Familiarity with the Graduate Attributes}

Participants were asked if they were familiar with the CEAB graduate attributes, and given four answers from which to choose, that included No, Somewhat, Yes, and Very descriptions (see Section 3.1 Survey Development). Only one participant out of 219 did not select an answer. Table 4 demonstrates the results.

Table 4: Familiarity with CEAB Graduate Attributes.

\begin{tabular}{|c|c|c|c|c|c|c|}
\hline & & $\begin{array}{l}\text { No } \\
(\# / \%)\end{array}$ & $\begin{array}{l}\text { Some- } \\
\text { what } \\
(\# / \%)\end{array}$ & $\begin{array}{l}\text { Yes } \\
(\# / \%)\end{array}$ & $\begin{array}{l}\text { Very } \\
(\# / \%)\end{array}$ & Total \\
\hline \multirow{3}{*}{$\begin{array}{l}\text { Stake- } \\
\text { holder } \\
\text { group }\end{array}$} & Students & $\begin{array}{r}61 \\
49.2 \%\end{array}$ & $\begin{array}{r}57 \\
46.0 \%\end{array}$ & $\begin{array}{r}5 \\
4.0 \%\end{array}$ & $\begin{array}{r}1 \\
0.8 \%\end{array}$ & 124 \\
\hline & Faculty & $\begin{array}{r}2 \\
4.3 \% \\
\end{array}$ & $\begin{array}{r}14 \\
30.4 \% \\
\end{array}$ & $\begin{array}{r}19 \\
41.3 \% \\
\end{array}$ & $\begin{array}{r}11 \\
23.9 \% \\
\end{array}$ & 46 \\
\hline & Industry & $\begin{array}{r}20 \\
41.7 \%\end{array}$ & $\begin{array}{r}19 \\
39.6 \%\end{array}$ & $\begin{array}{r}9 \\
18.8 \%\end{array}$ & $\begin{array}{r}0 \\
0 \%\end{array}$ & 48 \\
\hline \multicolumn{2}{|l|}{ Total } & $\begin{array}{r}83 \\
38.1 \%\end{array}$ & $\begin{array}{r}90 \\
41.3 \%\end{array}$ & $\begin{array}{r}33 \\
15.1 \%\end{array}$ & $\begin{array}{r}12 \\
5.5 \%\end{array}$ & 218 \\
\hline
\end{tabular}

Forty-nine percent of students either hadn't heard of the CEAB graduate attributes, or had heard of them but couldn't recall them. Forty-six percent of students knew a few of the graduate attributes; four percent knew them and could list them, and less than one percent of students were very familiar with the graduate attributes. Four percent of faculty either hadn't heard of the CEAB graduate attributes, or had heard of them but couldn't recall them. Thirty percent of faculty were somewhat familiar with the graduate attributes; and fifty percent of faculty were familiar or very familiar with the graduate attributes. Forty-two percent of industry members either hadn't heard of the CEAB graduate attributes, or had heard of them but couldn't recall them. Forty percent were somewhat familiar; nineteen percent were familiar, and no industry member perceived that they were very familiar with the CEAB graduate attributes.

\section{DISCUSSION}

Perceptions are personal opinions, influenced by the way that people view and interpret their own knowledge, their learning experiences and goals, their expectations, the place from which they experienced instruction and learning, and the level of autonomy that they have to direct the instruction and learning [27]. Personality can change perceptions. For example, a person whose orientation is for individual expertise will believe that they have acquired more knowledge and better abilities than counterparts of lower drive [28]. Furthermore, how persons react to their perceptions will vary their experiences, and thus responses [27]. Perceptions also differ between respondents who have different primary functions within the educational equation. For example, as suggested by a history of research, faculty and students often perceive educational efforts and methods differently [29]. Therefore, perceptions between different stakeholders, i.e., students, faculty and industry, are likely to be varied [27].

Due to the potential differences in perceptions in the educational equation, it becomes essential to understand engineering stakeholders' acuities regarding the relative importance and dependencies of the graduate attributes, so that misconceptions or differences can be revealed, common understandings found, and ultimately, curricula can be improved. This is especially important in education, as the intended curriculum is not inevitably the learned curriculum [7][30]. This research is intended to prompt consideration and discussions amongst engineering stakeholders of the Faculty of Engineering at the University of Manitoba regarding their understandings of the $12 \mathrm{CEAB}$ graduate attributes, in order to inform common understandings and best practices in outcomes-based education. Outcomes-based education is a process that continually focuses on student learning and demands institutions to be accountable to the evidence of the learning [31]. Based on the findings regarding stakeholders' perceptions of their familiarity with the graduate attributes, it would seem that more work needs to be done to familiarize our engineering stakeholders about the CEAB graduate attributes, particularly students and industry. 
Research shows that there is a growing awareness of the value of outcomes-based pedagogical practices, not only for enhancing student learning [32], but also for enriching program quality [33]. The outcomes-based pedagogy born out of the new CEAB accreditation criteria is meant to be a dynamic process: a continuous cycle of assessment and program improvement [8] [34] $[35][36][37][38][4]$. To achieve effective outcomesbased education, it stands to reason that the stakeholders required to develop these outcomes should be cognizant of what these outcomes are.

Part of the requirements in the new outcomes-based accreditation process is to involve all engineering stakeholders in the institution's outcomes-based assessment and continual improvement process [5]; this is indicative of the institution's commitment to accountability [39]. Indirect assessment data should be gathered from faculty, students, alumni and industry in order to triangulate direct assessments, but there are other, valuable reasons for involving the engineering community: By providing opportunity for feedback, faculty demonstrates its partnership, goodwill, and accountability to their engineering stakeholders [40]. Students provide indispensible feedback as consumers of their education, and given the opportunity, relish the chance to be part of the discussion that leads to program improvement and gives them some autonomy in the course of their own learning. Faculty members, who are integral to the improvement process, are more likely to buy-in to outcomes-based assessment if their own perceptions and expectations are heard [31]. And industry members provide indispensible front-line feedback as they hire new engineering graduates, and are in the unique position to assess new graduates' outcomes post-graduation [38][41][1]. This is especially significant as a majority of engineering graduates proceed to work in industry [42] [40].

Part of the success of any new initiative is the establishment of a common language and a shared understanding [9][2]. This is especially so when the goal is to create faculty buy-in when founding an assessment protocol. A common language leads to a shared understanding and the development of a common set of expectations [9]. Unclear or dissimilar understandings can sabotage the installation of a successful outcomesbased assessment protocol [2].

A collective language that supports the comprehension and expectancies of students and faculty is essential, especially when assessing student outcomes. Indeed, this is an area of particular importance as when considering that the history of research indicates that students and faculty do not share similar perceptions in regards to pedagogical methods and practice [29]. This has even greater emphasis when it comes to assessment, where large differences in the perceptions of students versus faculty were found when their perceptions of efficacy and usefulness of assessments of learning were explored [29].

The significance of establishing a common language extends to other engineering stakeholders as well. Research shows that while academics and industry are striving to establish a shared understanding in regards to employability skills for graduates, there is still a chasm between the two groups [43]. The same holds true for the language academics use compared to industry [44]. If the language of academics and industry are different, then it is quite possible that the expectations will differ as well [40].

It is fundamental to understand faculty, student and other engineering stakeholders' expectations and perceptions when it comes to the 12 CEAB graduate attributes and the development of reliable and valid assessment practices, and language will be the conduit. How each of these groups defines, understands, and recognizes the attributes must be established in order to validly and reliably assess student attribute competencies [29]. In the end, understanding the differences around how each of the engineering stakeholders defines the essential attributes in engineering will create fusion between the groups and lead to a deeper appreciation for and insight into the profession of engineering [45]. Therefore, establishing a common knowledge and understanding of the graduate attributes for all of our engineering stakeholders is paramount. The preliminary findings from this research study demonstrate that this is still an area that we must pursue.

\section{NEXT STEPS}

From the findings of Phase 1, the beginnings of a theoretical/conceptual framework will be developed, which will be held up to a qualitative investigation of the three engineering stakeholder groups' responses to the framework in Phase 3. In Phase 2, the Department of Biosystems in the Faculty of Engineering will be targeted to examine the content validity of the graduate attributes in their program curriculum against the attribute relative importance and dependencies as established in Phase 1.

\section{CONCLUSIONS}

This research represents the $\mathrm{PhD}$ thesis of the lead author. The greater study is designed as a mixed-methods explanatory case study. The overarching objective is to explore whether the CEAB graduate attributes are emphasized in the engineering programs in the Faculty of Engineering at the University of Manitoba in the most optimal way. The study will be executed in three phases. The first phase is designed to determine the relative importance and the levels of dependencies of the graduate attributes across three engineering stakeholder groups: faculty, students and industry members. In this 
paper, the design and methodology of the first phase of the study were explained, and some preliminary findings on participants' perspectives of their graduate attribute familiarity were presented.

The initial findings from this study will enable engineering stakeholders to contemplate their own understandings regarding the CEAB graduate attributes. Investigating individual stakeholders' understandings of the graduate attributes will help to establish a common knowledge and understanding of them amongst our student, faculty, and industry stakeholders. The early findings from this study indicate that work to develop a common knowledge about the CEAB graduate attributes needs to continue.

\section{Acknowledgements}

The lead author thanks her advisor, Dr. Sandra Ingram, for her continual support and guidance throughout her $\mathrm{PhD}$ education. She extends her gratitude to Dr. Danny Mann for his support and provision of numerous research and teaching opportunities. She thanks Dr. Robert Renaud for his invaluable contributions to the design of this research study.

\section{References}

[1] J. W. Prados, G. D. Peterson, and L. R. Lattuca, "Quality assurance of engineering education through accreditation: The impact of engineering criteria 2000 and its global influence," Journal of Engineering Education, vol. 94, no. 1, pp. 165-184, 2005

[2] G. Rogers, "EC2000 and measurement: How much precision is enough?," Journal of Engineering Education, vol. 89, no. 2, pp. 161-166, 2000.

[3] B. Olds, B. Moskal, and R. Miller, "Assessment in engineering education: Evolution, approaches and future collaborations," Journal of Engineering Education, vol. 94, no. 1, pp. 13-25, 2005.

[4] D. C. Davis, K. L. Gentili, M. S. Trevisan, and D. E. Calkins, "Engineering design assessment processes and scoring scales for program improvement and accountability," Journal of Engineering Education, vol. 91, no. 2, pp. 211-221, 2002.

[5] Engineers Canada, Accreditation. 2014. Available as of April 14, 2014 from http://www.engineerscanada.ca/accreditationresources

[6] B. Frank, S. McCahan, C. K. Watts, S. Fostaty Young, P. Ostafichuck, P. Wolf, and N. Saleh. Engineering graduate attribute development (EGAD) project. 2011. Available as of April 14, 2014 from

http://engineering.queensu.ca/egad/index.php

[7] B. Frank and S. Fostaty-Young, "What can our students do: Year 2 of graduate attribute assessment at Queen's University," in Proc. CEEA Canadian Engineering Education Conf., CEEC11, Andy Fisher (ed.) (St. John's, NL; 6-8 June 2011), 6 pp., 2011.

[8] S. McCahan, L. Romkey, and G. Allen, "Development of the graduate attribute quality assurance process at the University of Toronto," in Proc. CEEA Canadian Engineering Education Conf., CEEC11, Andy Fisher (ed.) (St. John's, NL; 6-8 June 2011), 6 pp., 2011.

[9] J. McGourty, C. Sebastian, and W. Swart, "Developing a comprehensive assessment program for engineering education," Journal of Engineering Education, vol. 87, no. 4, pp. 355361,1998 .

[10] J. Biggs, "What the student does: Teaching for enhanced learning," Higher Education Research and Development, vol. 18, no. 1, pp. 57-75, 1999.

[11] C. Miller, L. Geraci, J. Jong, L. Qing, C. Hickman, and S. Kuchta, COE Forum: Design Thinking: Business Programs: Industry Future Series. Education Advisory Board: The Advisory Board Company (eab.com), 2014, 20 pp. Available as of January 20, 2017 from https://www.eab.com//media/EAB/Research-and-Insights/COE/SuccessPages/2016/Design-Thinking-Business-Programs-WhitePaper.pdf

[12] J. W. Creswell, Qualitative inquiry and research design: Choosing among five approaches. L.A., CA: Sage, 2013 (3 $3^{\text {rd }}$ ed.), pp. \{ISBN: 978-1-4129-9530-6\}

[13] M. Borrego, E. Douglas, and C. Amelink, "Quantitative, qualitative and mixed research methods in engineering education," Journal of Engineering Education vol. 98, no. 1, pp. 53-66, 2009.

[14] M. Wright, T. Froese, and S. Nesbit, "Canadian civil engineering and sustainable development competence, in Proc. CEEA Canadian Engineering Education Conf., CEEC14, (Canmore, AB; 8-11 June 2014), 1 pp., 2014.

[15] N. van Note Chism, E. Douglas, and W. J. Hilson, Jr., Qualitative Research Basics: A Guide for Engineering Educators. Rigorous Research in Engineering Education: Creating a Community of Practice, National Science Foundation, U.S.A., 2008, 69 pp. Report Number DUE0341127.

[16] J. Turns and C. J. Atman, "Concept maps for engineering education: A cognitively motivated tool supporting varied assessment functions," IEEE Transactions on Education, vol. 43, no. 2, pp. 164-173, 2000. Available as of April 24, 2014 from http://ieeexplore.ieee.org/xpl/login.jsp?tp=\&arnumber=848069\& url=http $\% 3 \mathrm{~A} \% 2 \mathrm{~F} \% 2$ Fieeexplore.ieee.org\%2Fxpls\%2Fabs_all.js p\%3Farnumber\%3D848069

[17] A. Johri, "Conducting interpretive research in engineering education using qualitative and ethnographic methods," in Cambridge Handbook of Engineering Education Research, eds., 
A. Johri and B. M. Olds. New York, NY: Cambridge University Press, 2014, 2 pp. \{ISBN: 978-1-107-01410-7\}

[18] R. J. Polland, Essentials of survey research. 2005. Available as of April 4, 2014 from http://www.pointk.org/resources/files/Guidelines_on_Essentials _of_Survey_Research.pdf

[19] R. D. Renaud, “Assessing the content validity of a clinical competency exam in nursing," unpublished.

[20] J. A. Gliner, G. A. Morgan, and N. L. Leech, Research in Applied Settings. New York, NY: Routledge Taylor and Francis Group, 2009 (2nd ed.), 469 pp. \{ISBN: 978-0-8058-6434-2\}

[21] Friends of Engineering. 2010. Available as of May 12, 2017 from http://www.friendsofengineering.ca/mission/

[22] Research Aids: Sample Size Calculator. Creative Research Systems. The Survey System, 2012. Available as of October 28, 2015 from https://surveysystem.com/sscalc.htm

[23] G. A. Morgan, N. L., Leech, G. W. Gloeckner, and K. C. Barrett, IBM SPSS for Introductory Statistics: Use and Interpretation. New York, NY: Routledge, 2011 (4th ed.), 229 pp. \{ISBN: 978-0-415-88229-3\}

[24] R. D. Renaud, (private communication), Jan. 28, 2016.

[25] G. N. Soutar and J. P. Turner, "Students' preferences for university: A conjoint analysis," International Journal of Educational Management, vol. 16, no. 1, pp.40-45, 2002. Doi: 10.1108/09513540210415523. Available as of May 10, 2017 from http://dx.doi.org/10.1108/09513540210415523.

[26] K. Trigwell and K. Yasukawa, "Learning in a graduate attributes-based engineering course," in Proc. HERDSA Annual International Conference, (Melbourne, 12-15 July 1999) 10 pp., 1999.

[27] E. Maclellan, "Assessment for learning: The differing perceptions of tutors and students," Assessment and Evaluation in Higher Education, vol. 26, no. 4, pp. 307-318, 2001. Available as of July 11, 2014 from http://strathprints.strath.ac.uk/2427/

[28] C. K. Parsons, E. Caylor, and H. S. Simmons. "Cooperative education work assignments: The role of organizational and individual factors in enhancing ABET competencies and co-op workplace well-being," Journal of Engineering Education, vol. 94, no. 3, pp. 309-317, 2005.

[29] M. Holsapple, D. Carpenter, J. Sutkus, C. Finelli, and T. Harding, "Framing faculty and student discrepancies in engineering ethics delivery," Journal of Engineering Education vol. 101, no. 2, pp. 169-186, 2012.

[30] M. Borrego and J. Bernhard, "The emergence of engineering education research as an internationally connected field of inquiry," Journal of Engineering Education, vol. 100, no. 1, pp. 14-47, 2011.
[31] A. Driscoll and S. Wood, Developing Outcomes-based Assessment for Learning-centered Education: A Faculty Introduction. Sterling, VA: Stylus, 2007, 275 pp. \{ISBN: 157922-194-7\}

[32] A. C. Heinricher, J. E. Miller, L. Schachterle, N. K. Kildahl, V. Bluemel, and V. Crawford, "Undergraduate learning portfolios for institutional assessment," Journal of Engineering Education, vol. 91, no. 2, pp. 249-253, 2002.

[33] J. W. Prados, G. D. Peterson, and L. R. Lattuca, "Quality assurance of engineering education through accreditation: The impact of engineering criteria 2000 and its global influence," Journal of Engineering Education, vol. 94, no. 1, pp. 165-184, 2005.

[34] S. K. Dew, M. Lavoie, and A. Snelgrove, "An engineering accreditation management system," in Proc. CEEA Canadian Engineering Education Conf., CEEC11, Andy Fisher (ed.) (St. John's, NL; 6-8 June 2011), 6 pp., 2011.

[35] A. F. Almarshoud, "Developing a rubric-based framework for measuring the ABET outcomes achieved by students of electric machinery courses," International Journal of Engineering Education, vol. 27, no. 4, pp. 859-866, 2011.

[36] J. E. Spurlin, S. A. Rajala, and J. P. Lavelle, “Assessing student learning," in Designing Better Engineering Education Through Assessment, eds. J. E. Spurlin, S. A. Rajala, and J. P. Lavelle. Sterling, VA: Stylus, 2008, pp. 23-58. \{ISBN: 978-157922-213-0\}

[37] J. Fredericks Volkwein, L. R. Lattuca, P. T. Terenzini, L. C. Strauss, and J. Sukhbaatar, "Engineering change: A study of the impact of EC2000," International Journal of Engineering Education, vol. 20, no. 3, pp. 318-328, 2004.

[38] N. Soundarajan, "Preparing for accreditation under EC2000: An experience report," Journal of Engineering Education, vol. 91, no. 1, pp. 117-123, 2002.

[39] P. Wolf and W. Stiver. 2011. Graduate attributes: Intentional mapping and assessment portfolios," in Proc. CEEA Canadian Engineering Education Conf., CEEC11, Andy Fisher (ed.) (St. John's, NL; 6-8 June 2011), 4 pp., 2011.

[40] K. Ferens, J. Seniuk Cicek, N. Sepehri, W. Kinsner, J.P. Burak, A. Parker, D. McNeill, D. Ruth, I. Jeffrey, N. Godavari, and S. Ingram, "Industry Forum III: Towards a common language," in Proc. CEEA Canadian Engineering Education Conf., CEEC14, (Canmore, AB; 8-11 June 2014), 7 pp., 2014.

[41] J. Shaeiwitz "Outcomes assessment in engineering education," Journal of Engineering Education vol. 85, no. 3, pp. 239-246, 1996.

[42] Engineering Industry Profile Graduates. Industry Profiles, 2014. Available as of April 12, 2014 from http://www.grb.uk.com/engineering-industry-profile

[43] K. Lowden, S. Hall, D. Elliot, and J. Lewin, The Employers' Perceptions of Employability Skills of new Graduates. London, 
EN: Edge Foundation, 2011. Available as of April 12, 2014 from http://www.edge.co.uk/media/63412/employability_skills_as_pdf _-_final_online_version.pdf

[44] B. Engeler Newbury, "Speaking in tongues: the gap between academic language and industry language," in Language in the disciplines: Disciplinary discourses and the embedding of academic literacy skills within programs, an Academic Literacy Teaching and Research Network (ALTAR) Symposium. (Hawthorn, Victoria, AU; 14 November) 2010.

[45] R. S. Heller, C. Beil, K. Dam, and B. Haerum, "Student and faculty perceptions of engagement in engineering," Journal of Engineering Education, vol. 99, no. 3, pp. 253-261, 2010. 